\title{
Outsourcing of Regulatory Affairs Tasks in Pharmaceutical Companies-Why and What?
}

\section{Gummerus, Anu}

2016-03

Gummerus , A , Airaksinen, M , Bengtström , M \& Juppo , A 2016 , ' Outsourcing of Regulatory Affairs Tasks in Pharmaceutical Companies-Why and What? ' , Journal of Pharmaceutical Innovation, vol. 11 , no. 1 , pp. 46-52 . https://doi.org/10.1007/s12247-015-9235-4

http://hdl.handle.net/10138/161085

https://doi.org/10.1007/s12247-015-9235-4

publishedVersion

Downloaded from Helda, University of Helsinki institutional repository.

This is an electronic reprint of the original article.

This reprint may differ from the original in pagination and typographic detail.

Please cite the original version. 


\title{
Outsourcing of Regulatory Affairs Tasks in Pharmaceutical Companies-Why and What?
}

\author{
Anu Gummerus ${ }^{1}$ - Marja Airaksinen ${ }^{2} \cdot$ Mia Bengtström ${ }^{3}$ - Anne Juppo ${ }^{4}$
}

Published online: 30 September 2015

(C) Springer Science+Business Media New York 2015

\begin{abstract}
Purpose The purpose of this study was to investigate what kind of regulatory affairs tasks is outsourced in the pharmaceutical industry and what are the reasons for outsourcing in the EU countries.

Methods The study was conducted as an e-mail survey in the pharmaceutical industry in Finland, Sweden, Estonia, Germany, and Spain, focusing on those companies that undertake regulatory affairs.

Results The survey received 71 completed responses out of 147 , a response rate of $48 \%$. The most outsourced tasks were related to translations of product information texts $(75 \%$ of the respondents). The principal reason for outsourcing regulatory affairs tasks to a Contract Research Organization (CRO) was the excessively heavy workload in the company's regulatory affairs. Also, outsourcing should be cost-effective. The fact that the $\mathrm{CRO}$ has experience and knowledge was seen as a very important requirement when choosing the $\mathrm{CRO}$ partner. Personal, individual contacts were mentioned in many of the open-ended responses as an essential criterion in the selection of the CRO.

Conclusions This survey indicated that outsourcing in regulatory affairs will continue. The quality of the CRO has a significant role when the companies select their partner. The
\end{abstract}

Anu Gummerus

anu.gummerus@gummerus.com

Oy Medfiles Ltd, Hatanpään valtatie 26 A, 33100 Tampere, Finland

2 Faculty of Pharmacy, University of Helsinki, Helsinki, Finland

3 Pharma Industry Finland, Helsinki, Finland

4 Formulation and Industrial Pharmacy Unit, Faculty of Pharmacy, University of Helsinki, Helsinki, Finland
CRO has to assure uniform quality of their personnel knowledge and skills in regulatory affairs, i.e., when the person in charge of the outsourced task changes in the CRO. Practically all product development steps can be outsourced by hiring local and multinational CROs. The companies should plan the outsourcing carefully and compare possible CROs even if the company has no plans to outsource at present.

Keywords CRO $\cdot$ Pharmaceutical industry $\cdot$ Regulatory affairs $\cdot$ Outsourcing

\section{Introduction}

The pharmaceutical industry has a long tradition in outsourcing. About 30 years ago, the outsourcing strategy was adopted to formulation, clinical trials, and registration. In the last 10 years, outsourcing has expanded to include most development and registration processes. Outsourcing has been practiced where capacity and specialist techniques and knowhow are required. Pharmaceutical research, development, and manufacturing processes as well as quality control can and are the subject of regular outsourcing from the largest to the smallest of pharmaceutical companies [5].

According to Piachaud [16], the increasing proportion of pharmaceutical R\&D being outsourced would drive future growth of the Contract Research Organization (CRO) sector by $10-12 \%$. A recent study by Cutting Edge Information in the USA [6] shows that outsourcing has become more common for regulatory affairs tasks. This study found that the top 50 pharmaceutical companies have increased their regulatory affairs budgets by an average of $27 \%$ during the years 2010 2012. The percentage of outsourcing regulatory affairs budgets in pharmaceutical companies had increased to $68 \%$. According to Cutting Edge Information, small drug 
manufacturers, as well as medical device companies, also concurrently increased their regulatory affairs budgets. Top 20 pharmaceutical companies reported that outsourcing consumes approximately $10 \%$ of the overall regulatory affairs budget. In order to utilize resources more efficiently in an increasingly competitive environment, the pharmaceutical industry is outsourcing a large volume of drug development activities to CROs. From the global perspective, the companies have started to use India and China as the most popular offshore locations in the past 3 or 4 years [7, 18, 19]. On the other hand, domestic outsourcing is a fast-emerging strategy among US firms. It means that the outsourcing is returned to the USA and is performed by the company or its strategic alliance [15].

There are two main models to outsource pharmaceutical processes. Strategic outsourcing enables pharmaceutical companies to focus on their core strengths and long-term goals. By outsourcing in this way, companies aim to maintain high-level expertise and to reduce the number of internal staff involved in those processes that are outsourced. As a result, strategic partnerships between a company and a CRO can offer the company an opportunity to have more flexible internal resources. Strategic outsourcing also provides expertise, competency, or resources that the company may not otherwise have. The CRO has to be selected carefully because the service sector and quality of CROs can vary depending on what services are needed and what are the cultural aspects. If the collaboration is successful, there may be a shift from capacity- to competence-based outsourcing. According to Clemens [3], a lot of pharmaceutical companies currently focus on only a few full-service CROs within a strategic partner-based relationship. The company's workload is hereby optimized, and the internal resources can focus on assuring the overall performance of the CRO.

Tactical outsourcing, which means contracting out work on a project-by-project basis, is often related to short-term projects. These projects cannot be handled internally due to a lack of internal capacity or resources allowing streamlining processes. According to the literature review $[3,8,11,12]$, this model is fading, but apparently not all outsourcing is strategic; contracts of both models continue to be employed relative to the company's specific requirements and outsourcing strategy. Companies see themselves as taking a more strategic, rather than tactical, or case-by-case, projectto-project approach to outsourcing with most planning to continue this approach. Preferred CRO lists have become important for a large percentage of respondents; roughly $45 \%$ of company respondents say that more than half of their outsourcing budget currently goes to preferred CROs in the year 2014 [4] (Table 1).

Prior research has shown that the outsourced [16-18] and backsourced tasks $[9,20]$ in the pharmaceutical industry have been widely studied. Research on outsourcing in the pharmaceutical industry has focused mainly on the economic benefits of the practice [1]. According to the literature review, the outsourced tasks of preclinical, clinical, manufacturing, and quality control activities have been studied, while the utilization of CROs in performing regulatory activities has been of less common interest [2]. Outsourcing of regulatory affairs is still a growing trend. Regulatory intelligence is a critical part of the success of the pharmaceutical development process. If the company or the CRO is unable to define the most suitable regulatory affairs process and the correct documentation, marketing authorization for the product can be delayed significantly. Therefore, it is useful to study, by scientific research, what regulatory affairs tasks have been outsourced and what are the service requirements for a CRO. Regulatory affairs services can range from simple tasks to very complex projects involving detailed consultation with relevant guidelines and/or concerned health agencies. As for the decentralized and mutual recognition procedures, outsourcing certain assessment activities and using expert networks among the agencies in a more flexible way could improve the use of resources [13].

A few common models for outsourcing regulatory affairs services are as follows:

1. Personnel augmentation for expanding current capacity to meet short-term business needs. The company can rent staff in-house from CRO. This model helps the company by

Table 1 Examples of strategic and tactical outsourcing of regulatory affairs

\begin{tabular}{ll}
\hline Tactical & Strategic \\
\hline$\checkmark$ Writing and reviewing of pharmaceutical-chemical documentation & $\checkmark$ Regulatory intelligence \\
& $\checkmark$ eRegulatory intelligence \\
$\checkmark$ Preparation and compilation of marketing authorization documentation & $\checkmark$ Regulatory maintenance of marketing authorization on \\
& behalf of marketing authorization holder \\
$\checkmark$ Preparation and compilation of active master files & $\checkmark$ Coordination of global submissions \\
$\checkmark$ SOP writing and training concerning regulatory issues & $\checkmark$ Regulatory authority liaison (e.g., regulatory consultation within \\
& the company, scientific advice meeting with the authorities) \\
\hline
\end{tabular}

Modified from Miller [12] 
allowing its core resources to concentrate more on new developments and regulatory strategies across the development pipeline.

2. Project-based outsourcing is a task-oriented activity where outsourcing is limited to specific tasks. Companies may outsource a particular project. CRO takes control of the outsourced activity and becomes responsible for its success. Examples could be a compliance project such as consistency between national summary of product characteristics and core company safety information or manufacturing and compliance information in national dossiers versus what the manufacturing site does.

3. Full-service submission outsourcing, which is suitable for post-marketing activities such as variations, PSURs, annual reports, and renewals.

4. Functional submissions, which are applicable for premarketing submissions for clinical trial applications, marketing authorization applications, new drug applications, abbreviated new drug applications, and different marketing authorization procedures such as mutual recognition, decentralized, and centralized procedures.

The purpose of this study was to investigate what kind of regulatory affairs tasks the pharmaceutical industry outsources and what are the reasons for the outsourcing in five EU countries.

\section{Methods}

The study was performed as an e-mail survey in the pharmaceutical industry in Finland, Sweden, Estonia, Germany, and Spain, focusing on those companies that undertake regulatory affairs. The countries concerned were selected in order to represent different European Union countries: Finland and Sweden are Nordic countries, Estonia joined the EU in 2004, while Germany and Spain are big economies in the EU. There are also cultural differences between the north and south parts of the EU, which gives greater variety to the countries chosen for this study.

The survey was designed to cover the main questions relating to the present outsourcing situation and the reasons, advantages, disadvantages, and future of outsourcing of regulatory affairs. Some of the questions were emphasized by Piachaud's study of outsourcing in the pharmaceutical manufacturing process, which was performed in 2002 [16]. Piachaud's study was conducted among the pharmaceutical industry, and some of the questions were also appropriate for this study. The survey consisted of structured questions, and where applicable, an open field was included to allow the respondents to indicate issues that were not included in the structured question. In addition, space was made available for open responses/comments at the end of the survey. Some of the questions were designed so that the respondent was able to select multiple options. Anonymity was required due to the confidentiality issues relating to the pharmaceutical industry. Therefore, the anonymity of the respondents was also assured in this questionnaire. For quantitative analysis of the responses, multiple-choice responses were categorized on a five-point Likert scale. A "no-opinion" option was added to ensure that "neutral" was not selected for no-opinion answers. These no-opinion answers were not taken to account when calculating the average value.

To assure face validity of the questionnaire, a pilot survey was conducted in late 2010. The pilot survey was sent to five academic and/or industrial experts. The responses of the pilot study were not included in the results of the final study. Two comments were received concerning the linguistic form of the questionnaire. After making the suggested changes to the content of the questionnaire, the main phase on the survey started in March 2011 and ended in August 2011. The list of responding pharmaceutical companies was provided by Pharma Industry Finland. The corresponding organizations from Sweden, Estonia, Spain, and Germany provided their regulatory affairs contact list. Generic Medicines Association Finland also provided their regulatory affairs contact list. The companies represented all sorts of companies: innovation based and generic companies, large, international companies, subsidiaries, CROs, CMOs, and small/medium-sized standalone companies. If the regulatory affairs director or manager or a person of similar authority was not known, the questionnaire was sent to the quality or clinical manager or a person of similar authority. The questionnaire was sent to one person in each company. The responding to the survey was done electronically via Helsinki University E-survey tool. The results were analyzed with SPSS and transferred to Excel software for quantitative analysis. The results are presented as percentages and frequencies. Responses to the open-ended questions were content analyzed by grouping similar themes and ideas [14]. Some representative responses are referred to in the "Results" section.

\section{Results}

In total, the survey received 71 completed responses out of 147 questionnaires sent, giving a response rate of $48 \%$. The majority (59 out of 147) of responses were received from Finland and Sweden (Table 2).

The response rate in Estonia was poor, $9 \%$, although the questionnaire was sent three times. When the results were studied closely, there was no difference if the respondent was from Finland, Sweden, or other countries. For this reason, results from different countries were combined.

Most of the respondents ( $80 \%$ ) worked in a subsidiary of a worldwide, international company. This reflects the fact that 
Table 2 Location of the pharmaceutical companies responding to the survey $(n=71)$

\begin{tabular}{llll}
\hline Country & $\begin{array}{l}\text { Number of sent } \\
\text { questionnaires }(n)\end{array}$ & $\begin{array}{l}\text { Responses } \\
\text { received }(n)\end{array}$ & $\begin{array}{l}\text { Response } \\
\text { rate }(\%)\end{array}$ \\
\hline Finland & 46 & 29 & 63 \\
Sweden & 64 & 30 & 47 \\
Estonia & 22 & 3 & 9 \\
Spain & 6 & 4 & 67 \\
Germany & 9 & 5 & 55 \\
Total & 147 & 71 & \\
\hline
\end{tabular}

there are not many headquarters located in the countries involved in this survey. Moreover, $64 \%$ of the companies that responded had proprietary products for human use (85\% human medicines). Many of the respondent companies also dealt with medical devices (48 \%).

Most commonly, the responder was a person with the title "head of the regulatory affairs" (62\% of the respondents), but there were also several other titles, e.g., regulatory affairs manager or similar (22\%), head of the company (5\%), and other titles $(10 \%)$, such as head of quality assurance, senior regulatory manager, responsible pharmacist, vice president or clinical development, and regional regulatory affairs head. The questionnaire reached well the persons in charge of the company's regulatory affairs functions although the titles depend on the organizational structure of the company.

\section{The Reasons for Outsourcing}

The principal reason for outsourcing the regulatory affairs tasks to a CRO was too heavy workload in the company's regulatory affairs (strongly agree $55 \%$ ) (Table 3 ).

Too heavy workload can be caused by companies' strategic and/or tactical outsourcing decision. The fluctuation of the workload is difficult to estimate. One comment to the openended field expressed that "the management of the company has a lack of knowledge whereas on the low level the employees have too heavy workload periodically."

Naturally, the outsourcing should be cost-effective, and this was also a finding of this study ( $27 \%)$. This study did not take a stand on actual costs, but the companies expect to gain financial benefit from outsourcing.

The strategic decision of a company to outsource regulatory affairs was not seen as an important reason to outsource regulatory affairs tasks. The companies have in-house knowledge of regulatory affairs, but country-specific expertise is desired. One open-ended outlined what really is required from CROs: "helping in product text translations for variation applications."

\section{Criteria for Selection of CRO}

Big pharmaceutical companies need CROs in situations involving lack of resources, whereas smaller companies are dependent on the overall know-how of the CRO, which can provide more general help in addition to the acquired specific service. The requirements of the $\mathrm{CRO}$ were defined according to CRO's experience and knowledge, size of CRO, cost-effectiveness, location, how well it is known, recommendation, eSubmission tools, and partnership network (Fig. 1).

The fact that CRO has experience and knowledge was seen as a very important requirement $(98 \%)$ when choosing a CRO partner. It was also asked if the size or location of CRO was a significant issue, but the respondents did not see this as important. According to the responses, it was not relevant if the CRO had eCTD database or if CRO had a global partnership network. The recommendation of CRO from other pharmaceutical company was acknowledged. The selection of the CRO was based on recommendations $(80 \%)$ or the prestige of the CRO (69\%). The companies searched for CROs also on the internet, but only $28 \%$ of the respondents answered this to be common practice. Moreover, $10 \%$ of the respondents reported that they collect information about CROs at exhibitions and/or congresses.

The open-ended responses revealed that the headquarters of international pharmaceutical companies evaluate the CROs and also choose the local CROs. If the selection is done at local subsidiary level, personal contacts from common professional history or the company's own CRO network are used. The personal, individual contacts were mentioned in many of the open-ended responses as important criteria for the selection of the CRO. Responses received from Finland specifically mentioned that workforce with regulatory affairs skills is

Table 3 The reasons for outsourcing (mean, 1=strongly disagree, $5=$ =strongly agree)

\begin{tabular}{lll}
\hline Reasons for the outsourcing of the regulatory affairs & Likert rating (1-5) (mean value) & Standard deviation \\
\hline Too heavy workload in the regulatory affairs department of the company & 4.4 & 0.9 \\
Cost-effectiveness & 2.8 & 1.2 \\
Company's strategic decision to outsource the regulatory affairs & 2.6 & 1.4 \\
Company has not enough knowledge of the regulatory affairs & 2.1 & 1.3 \\
\hline
\end{tabular}


Fig. 1 The requirements for CRO (mean, $1=$ strongly disagree, $5=$ strongly agree)

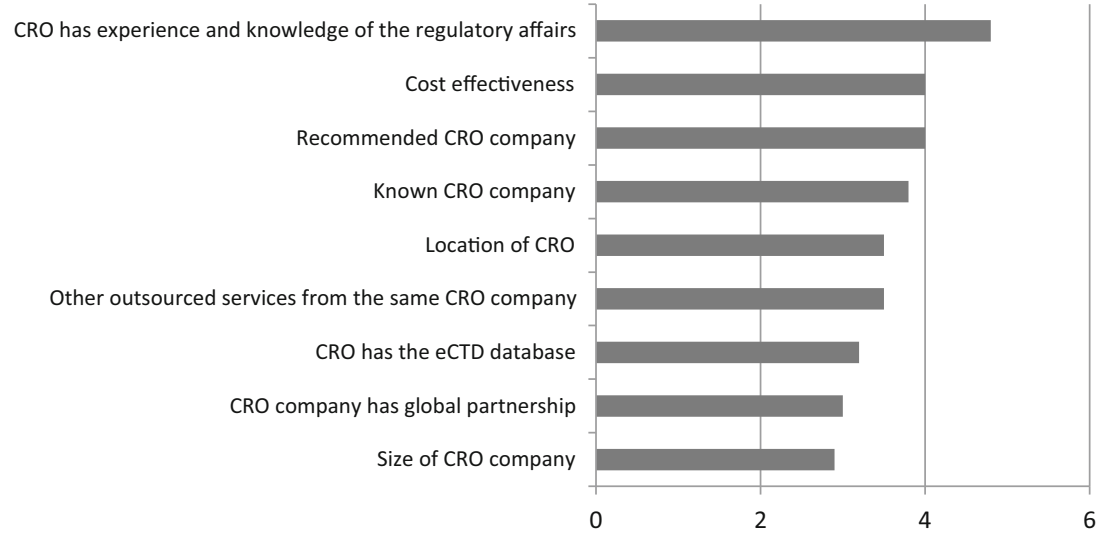

"easy to get because there are only three professional CRO companies in Finland."

Given that the pharmaceutical industry is a highly regulated sector, it was not surprising that one respondent pointed out that "it is hard to find a CRO that would take full regulatory responsibility of a product; sometimes it easier to do it yourself than explain." This may also express a concern over the outsourcing partner involved and their qualities, or lack of them, such as ability and trustworthiness.

\section{The Outsourced Regulatory Tasks}

The most outsourced tasks were related to the translations of the product information texts. CROs have local language expertise for translating summaries of product characteristics (SmPC) and package leaflets (PLs), along with labeling texts (Fig. 2). Many of the international companies do not have their own subsidiary in the country or do not have translation capabilities, and therefore, a local contact is required. The outsourced translation procedure also helps reduce the workload in the company because CRO experts are used to translate the medicinal product information texts. This reduces the time spent on translation.
Related to the translations, almost half of the respondents reported that the readability testing of the PL has been outsourced to CROs. The readability test has to be done in a local language, and in these cases, a local CRO can conduct the user test. These tests are needed not only mostly for the new marketing authorization applications but also in case of extensive variation application concerning the product information texts.

As companies want to concentrate on core functions and new marketing authorization procedures, $44 \%$ of the respondent companies have outsourced the regulatory maintenance of marketing authorizations, i.e., full-service submission. CROs have full responsibility of regulatory maintenance of the products. The companies outsource submissions of the variation types I $(40 \%)$ and II (44\%) to CROs but prepare the renewals and notifications themselves. One fifth responded that they have outsourced the process of a new marketing authorization application in the decentralized/ mutual recognition procedure.

In some cases, it is more practical that the regulatory affairs expert from the CRO works inside the company. One fourth of the companies have used this kind of service. The expert inside the company has to have a wide experience to adopt the company's standard operation procedures in order to handle
Fig. 2 Regulatory affairs tasks that have been outsourced in the responding companies $(\%$ of the respondents)

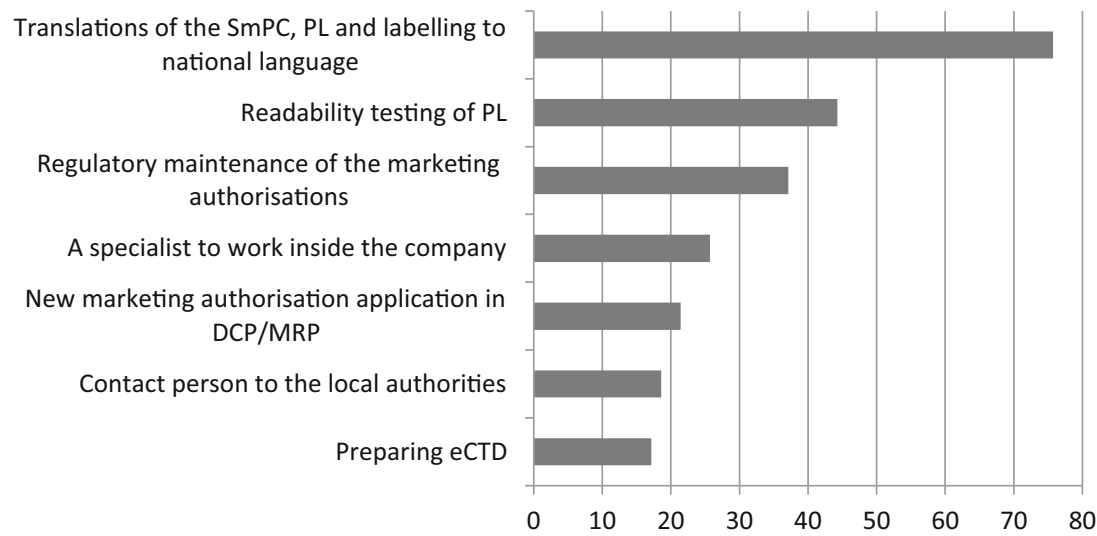


the outsourced work. This work may also contain duties that are not related to regulatory affairs but, e.g., to pharmacovigilance and marketing.

Other mentioned outsourced tasks consisted of harmonization of module 3 of the Common Technical Document (CTD structure), catalogue updates, especially in Nordic countries, and preparation of clinical trial applications.

\section{The Future of Outsourcing Regulatory Affairs Tasks}

The outsourcing of the regulatory affairs tasks will continue as $84 \%$ of the respondents said that they will outsource in the future. The services to be outsourced will be the same kind as mentioned earlier, but the regulatory maintenance for the products and new market authorization applications are also planned to be outsourced more than previously. According to the open-ended questions, two of the companies have not planned the outsourcing of the regulatory affairs tasks at any point but did respond that "in case of heavy workload outsourcing could be used." Seven of the companies replied that they have already outsourced regulatory affairs tasks to a CRO and will continue to outsource similar tasks as previously. The outsourcing of readability testing for PLs was also mentioned by two companies. According to the responses, $62 \%$ found that there are enough CROs to which regulatory affairs tasks can be outsourced.

\section{Discussion}

This survey was successful in giving a cross section of outsourcing regulatory affairs in the EU even though the survey respondents were mainly from the Nordic countries. In the concerned countries, companies need local contacts especially for translations. The tendency of outsourcing regulatory affairs seems to continue, but there are some references also from backsourcing tasks to companies. According to this survey, the pharmaceutical companies will outsource full-service submissions, i.e., post-marketing activities such as preparation and compilation of the variation applications, PSURs, annual reports, and renewals. The companies will focus on core functions and new marketing authorization procedures internally and coordinate these processes by themselves. The selection of the CRO is based on recommendation or the fact that the CRO is well known in the pharmaceutical industry. If the company does not have any collaboration with CROs or recommendations, they will search for information on the Internet. In some cases, the headquarters of the international pharmaceutical companies evaluate the CROs and also choose the local CROs. If the selection is done at local subsidiary level, personal contacts from common professional history or the company's own CRO network are used. It could be useful to repeat this survey regularly to see what are the chronological tendencies within the outsourcing.

Generally, and based on this study, CROs have to be conscious that the quality control of regulatory affairs tasks has to be in order to ensure the quality, safety, and efficient use of medicines and also to keep the customers satisfied. A competitive CRO with quality control points and standard operation procedure can gain a competitive edge over other CROs. CROs have to be in the forefront when regulatory affairs topics are discussed in order to achieve the expertise required. Before the CRO places their regulatory affairs expert in the company, the expert has to be trained by the CRO to handle the various predefined regulatory affairs tasks. Open-ended questions revealed that there are "individual differences between the hired employees." One comment suggested that the experts should have knowledge "from translations to FDA specialist knowledge." It seems that CRO experience is dependent on individual experience rather than the CRO per se. The clear scheme for training the personnel to perform possible tasks inside the company ensures that CRO provides good quality even if the employee has to be replaced during the agreement period.

The translation of texts also requires standard operation procedures from the CRO on the quality control of the translations. CROs might have their own translators, or they have a network for the translation procedure for different languages. The CRO has to have a strong and long-term expertise to perform the readability tests for PLs. Strong expertise is needed according to the study of Maat et al., which found that the leaflets were not user-friendly and contained problems related to finding relevant information [10]. The CRO is in a key role in proposing possible changes to the PLs.

The CRO has to be aware of the tight timelines for the tasks. The company often informs the CRO of the work tasks very close to the deadline. This is due the fact that the final decision dates informed by the authorities are not known or that the authorities can make changes for instance to the product information texts before the final decision. The responsibilities should be clearly defined when preparing the agreement between the company and the CRO. The timelines for the various tasks should also be specified to avoid the discrepancies between the expectations and realizations of the work tasks. This is very crucial, for instance, when there is an agreement for the translation procedures of the product information texts.

Referring to companies strategic decisions to outsource, it is essential that all sourcing decisions support the organization's overall business strategy and are revised accordingly as competitive conditions change [16]. According to the responses, it is essential that the personnel is informed and updated of the company's outsourcing strategy. Based on this study, the outsourcing decisions or the strategic decisions were not clearly informed to company's personnel. If the 
company's management does not have enough knowledge about the requirements and time-consuming tasks of regulatory affairs, the company has problems taking care of the regulatory affairs tasks without transferring these extra tasks to a third party. This might also reflect the relationships at a practical level when the company and the CRO personnel discuss the outsourcing of the tasks. This might lead to a rapid turnover of the company's or CRO's skilled employees to seek for jobs in companies where communication and strategies are more clear. The employees have to be treated respectfully, fairly, and equal in accordance with laws and culture. It is also necessary to create an environment that supports the development and well-being of every employee.

When the company plans for the outsourcing, the selection of CRO has to be done carefully. Outsourcing support services help companies become more efficient, have access to new skills and resources, and focus on the core business. Before selecting a CRO, the company has to define what tasks will be outsourced and to what extent the outsourcing will be done. The CRO that is chosen can be located in a different town or even country than the company itself, but it is practical if the CRO has local expertise in the country that is concerned. Problems in local language also trigger outsourcing of regulatory affairs tasks. The companies themselves want to focus on regulatory affairs strategies of their high priority products.

\section{Conclusion}

This survey indicated that the outsourcing in the regulatory affairs is common and will continue. Most of the companies in the EU have already outsourced these tasks to CROs. The quality of the CRO has a significant role when selecting the CRO. The CRO has to assure uniform quality of their personnel's regulatory affairs knowledge and skills, i.e., when the CRO regulatory affairs person changes in the outsourced task. Practically all product development steps can be outsourced by hiring local and multinational CROs. The companies should plan the outsourcing carefully and compare CROs even if the company has no plans to outsource at present. When planning and preparation has been done thoroughly, the outsourcing procedure is fluent and the responsibilities and responsibility issues are known without doubt.

There is some indication that pharmaceutical companies may be commencing to take back development activities inhouse because of the difficulties in managing outsourced innovation processes. The follow-up and control of outsourcing costs need to be studied more precisely in the future. According to the literature review, cost evaluation research in outsourcing of regulatory affairs has not been done. One important area for further research is the question of how moral responsibility is assigned in CROs. In some cases, there appears to be a clear disconnection between CROs and their clients when it comes to who should take responsibility when a failure is detected.

Conflict of Interest The authors declare that they have no conflict of interest.

\section{References}

1. Abodor H. Ethical issues in outsourcing: the case of contract medical research and the global pharmaceutical industry. J Bus Ethics. 2012;105:239-55.

2. Bates S, Sloan E. Outsourcing regulatory affairs activities: how a policy can drive good decisions. Drug Inf J. 2000;34:981.

3. Clemens N. Outsourcing in drug development. Drug Dev. 2010;5: 48.

4. Contract Pharma: outsourcing survey 2014. http://www. contractpharma.com/issues/2014-04-02/view_features/2014outsourcing-survey/\#sthash.REjeKhze.dpuf. Accessed 13 May 2014.

5. Crossley $\overline{\mathrm{R}}$. The quiet revolution: outsourcing in pharma. Drug Discov Today. 2004;16:694.

6. Cutting edge information: regulatory affairs: safeguarding submission success and product development strategy, 2012. http://www. cuttingedgeinfo.com/research/regulatory/market-approval. Accessed 20 Jan 2013.

7. Drabu S, Gupta A, Bhadauria A. Emerging trends in contract research industry in India. Contemp Clin Trials. 2010;31:419-22.

8. Kennedy T. Strategic project management at the project level. Clin Res Reg Aff. 2001;18:345-65.

9. Lowman $\mathrm{M}$ et al. Innovation risks of outsourcing in pharmaceutical new product development. Technovation. 2012;32:99-109.

10. Maat H, Lentz L. Improving the usability of patient information leaflets. Patient Educ Couns. 2010;80:113-9.

11. Mason J. Strategic alliances: partnering for success. Manag Rev. 1993;82:10.

12. Miller L. Commentary: outsourcing of regulatory activities: how a policy can drive good decisions. J Drug Inf. 2000;34:987-9.

13. Montpart Costa, E. Making the most of the EU's regulatory resources. Regul Aff J: Pharma 2009; 20.

14. Patton MQ. Qualitative evaluation and research methods. 2nd ed. Newbury Park: Sage Publications; 1990.

15. Pearce J. Why domestic outsourcing is leading America's reemergence in global manufacturing. Bus Horiz. 2014;57:27-36.

16. Piachaud B. Outsourcing in the pharmaceutical manufacturing process: an examination of the CRO experience. Technovation. 2002;22:81-90.

17. Piachaud B. Outsourcing technology. Res Technol Manag. 2005;48:40-6.

18. Quinn B. The outsourcing innovation: the new engine of growth. Sloan Manag Rev Summer. 2000;41:4.

19. Sherlock A. Outsourcing: China takes center stage. Appl Clin Trials. 2012;28-31:33.

20. Zirpoli F, Becker MC. The limits of designing and engineering outsourcing: performance integration and the unfulfilled promises of modularity. R\&D Manag. 2011;41:21-43. 